\title{
Erratum to: Epidemiology, costs, and burden of osteoporosis in Argentina, 2009
}

\author{
Francisco R. Spivacow • Ariel Sánchez
}

Published online: 18 August 2010

(C) International Osteoporosis Foundation and National Osteoporosis Foundation 2010

\section{Erratum to: Arch of Osteoporos}

DOI 10.1007/s11657-010-0038-4

The article unfortunately contained no data on global or "crude" rates of hip fractures in Argentina. The mean annual rates of hip fractures are 286/100,000 for women and 118/100,000 for men aged above 50 years, yielding a 2.42:1 F/M ratio. These figures supersede the rate of 488/ 100,000 inhabitants aged above 50 years $(\mathrm{SD} \pm 86)$ erroneously appearing in the Abstract and on the second page of the article (right-hand column, second line of section entitled "Hip fractures"). The authors regret their error.

The online version of the original article can be found at http://dx.doi. org/10.1007/s11657-010-0038-4.

F. R. Spivacow

Sociedad Argentina de Osteoporosis (SAO),

Instituto de Investigaciones Metabólicas (IDIM),

Buenos Aires, Argentina

\author{
A. Sánchez $(\bowtie)$ \\ Asociación Argentina de Osteología y Metabolismo Mineral \\ (AAOMM), Centro de Endocrinología, \\ Rosario, Santa Fe, Argentina \\ e-mail: asanchez@cimero.org.ar
}

